\title{
ESCOLAS ÉTNICAS POLONESAS NO RIO GRANDE DO SUL (1875-1939)
}

DOI: http://dx.doi.org/10.1590/2236-3459/45004

\author{
Adriano Malikoski \\ Universidade de Caxias do Sul, Brasil. \\ Lúcio Kreutz \\ Universidade de Caxias do Sul, Brasil.
}

$\cos 80$

\begin{abstract}
Resumo
Neste artigo tem-se por objetivo apresentar resultados de pesquisa sobre as escolas étnicas polonesas, organizadas no Estado do Rio Grande do Sul entre o período de 1875 e 1939 . Na história cultural como referência de leitura desse processo de ensino, privilegia-se a compreensão dos aspectos que envolvem a reconstrução do passado em uma narrativa, no cuidado e no tratamento das fontes. Essas escolas foram formadas por meio de características culturais da imigração polonesa, tais como língua, religião e outras instituições culturais. Estavam associadas ao esforço de proporcionar ensino elementar em comunidades homogêneas desse grupo de imigrantes, com traços culturais distintos, presentes em diversos municípios do Estado. Até pouco antes do processo de nacionalização do ensino, em 1938, estavam organizadas 128 escolas, com 4.560 alunos e 114 professores.

Palavras-chave: escolas étnicas polonesas, imigração polonesa, cultura e etnicidade.
\end{abstract}

\section{POLISH ETHNIC SCHOOLS IN RIO GRANDE DO SUL (1875-1939)}

\section{Abstract}

This paper aims to present research results of the Polish ethnic schools organized in the State of Rio Grande do Sul in the period between 1875 and 1939. In cultural history, which is a reading reference of the teaching process, emphasis is given to the aspects that involve the rebuilding of the past in a narrative, to the care and to the treatment of the sources. These schools were formed through cultural characteristics of polish immigration, such as language, religion and other cultural institutions. They were associated with the effort to provide elementary education in homogeneous communities of this group of immigrants, with distinct cultural traits in several municipalities in the state. Up to the teaching nationalization process, in 1938, were organized 128 schools, with 4560 students and 114 teachers.

Key-words: polish ethnic schools, polish immigration, culture and ethnicity. 


\section{ESCUELAS ÉTNICAS POLACAS EN RIO GRANDE DO SUL (1875-1939)}

\section{Resumen}

Este artículo tiene como objetivo presentar resultados de investigación de las escuelas étnicas polacas organizadas en el Estado de Rio Grande do Sul del período comprendido entre 1875 y 1939. La historia cultural como referencia de lectura de este proceso de enseñanza, hace hincapié en la comprensión de los aspectos relacionados con la reconstrucción del pasado en un relato, en el cuidado y tratamiento de las fuentes. Estas escuelas se formaron a través de las características culturales de la inmigración polaca, como idioma, religión y otras instituciones culturales. Estaban asociados no esfuerzo de proporcionar educación primaria en comunidades homogéneas de este grupo de inmigrantes, con rasgos culturales distintos en varios municipios del estado. Hasta poco antes del proceso de Nacionalización de Enseñanza en 1938, organizaron 128 escuelas con 4560 alumnos y 114 profesores.

Palabras clave: escuelas étnicas polacas, inmigración polaca, cultura y etnicidad.

\section{ÉCOLES ETHNIQUES POLONAISES EN RIO GRANDE DO SUL (1875-1939)}

\section{Résumé}

Cet article vise à présenter les résultats de la recherche sur les écoles ethniques polonais organisés dans l'État de Rio Grande do Sul, dans la période entre 1875 et 1939. Dans l'histoire culturelle comme référence la lecture de ce processus d'enseignement, l'accent est mis sur la compréhension du de nombreux aspects impliquant la reconstruction du passé dans un récit, dans les soins et le traitement des sources. Ces écoles ont été formés par des caractéristiques culturelles de l'immigration polonaise comme la langue, la religion et d'autres institutions culturelles. Ils ont été associés à l'effort à fournir une éducation élémentaire dans lesdites communautés homogènes de ce groupe d'immigrants, avec des traits et des cadeaux culturels distincts dans plusieurs municipalités de l'État. Juste avant le processus de nationalisation de l'enseignement en 1938 ont été organisées 128 écoles avec 4560 étudiants et 114 enseignants. Mots-clé: écoles ethniques polonais, immigration polonaise, culture et ethnicité. 


\section{Considerações iniciais}

$\mathrm{O}$ presente artigo tem como objetivo apresentar como se estruturou o processo de ensino da imigração polonesa no Rio Grande do Sul. O recorte temporal compreende a vinda dos primeiros imigrantes poloneses, a partir de 1875 , até a nacionalização compulsória do ensino, em 1939, destacando o processo de formação dessas escolas étnicas. $O$ corpus de pesquisa utilizado compreende entrevistas realizadas com ex-alunos, documentos de acervos históricos e referências sobre o tema nos Estados do Rio Grande do Sul, Paraná e Santa Catarina. Metodologicamente procedemos na perspectiva salientada por Paraíso (2012), no sentido de centrar a atenção na decomposição do que está construído, identificando, reunindo, recompondo, fazendo montagens, desmontagens, enfim, o realce da diferença e a invenção ou reinvenção de novos sentidos e significados, em que as fontes podem produzir em imagens e pensamentos sobre a educação.

A construção desta narrativa privilegia a compreensão do processo histórico por meio do simbólico e da significação de sentidos partilhados. Segundo Pesavento (2008) essa dimensão simbólica de análise permite a multiplicação das fontes, constituindo-se parte do processo historiográfico. Os símbolos e mitos são preservados, subsistem ao tempo e contribuem na construção das representações. Nesse sentido, entendemos que a verdade sobre determinado objeto, em tempo diverso do atual, é uma produção humana baseadas em representações e significados estabelecidos pelas fontes. Essa perspectiva aponta novos caminhos para construção ou reconstrução da história. Podemos repensar o objeto em questão, por meio de redes interdisciplinares, na aproximação direta do tempo histórico e na sua narrativa.

Porém, os conceitos de cultura e identidade étnica são importantes para estabelecermos uma relação interpretativa das fontes numa perspectiva de processo. Para Hall (2006), a concepção pós-moderna de identidade é uma "celebração móvel" (p. 12) formada e transformada continuamente, sendo definida historicamente: "o sujeito assume identidades diferentes em diferentes momentos" (p. 12).

Segundo Kreutz (2003) cultura e identidade são elementos dinâmicos que agregam significados construídos e processuais em que o real passa a ser construído também a partir do simbólico. Nesse contexto, a própria etnicidade também passa a ser compreendida como processo. Para Poutignat e Streiff-Fenart (1998) a etnicidade é um processo contínuo de construção e reconstrução, sem relações com característica biológicas, requerendo ser expressa e validada na interação entre os grupos. Não existem categorias a priori que definem que um indivíduo pertence a este ou aquele grupo. O que distingue um grupo social de outro são percepções que cada qual possui de si na interação social.

Segundo Hannerz (1997) os limites das fronteiras interétnicas estão relacionados com os múltiplos processos identitários e culturais, sem uma ordem fixa e estável: "a liberdade da zona fronteiriça é explorada com mais criatividade por deslocamentos situacionais e combinações inovadoras, organizando seus recursos de novas maneiras, fazendo experiências. Nas zonas fronteiriças, há espaço para a ação no manejo da cultura" (p. 24). 
Portanto, um processo escolar étnico pode ser formado na interação dialógica entre a consciência de pertencimento com os processos os identitários culturais espaçostemporais. No caso dessa pesquisa trata-se de um processo identitário que tem por cenário as condições dos núcleos rurais com expressivo número de imigrantes poloneses no Estado do Rio Grande do Sul.

\section{Herança escolar trazida junto com os imigrantes poloneses}

Para uma melhor compreensão da organização das escolas da imigração polonesa no Rio Grande do Sul é necessário levar em conta a herança escolar trazida por esses imigrantes dos territórios ocupados pela Rússia, Prússia e Áustria. Cada país dominante possuía certa especificidade em relação ao ensino escolar para com o grupo étnico polonês durante o movimento das primeiras levas de emigrantes com destino ao Rio Grande do Sul.

Em relação à região da Polônia sob domínio prussiano, para Wachowicz (2002) o principal problema foi o agrário. Esta situação influenciava diretamente o ensino escolar desse domínio, pois junto com a questão de desapropriação de terras havia um processo de despolonização em que a língua polonesa foi proibida nas escolas, nas igrejas, nas repartições públicas e em atos oficiais. Embora as escolas não fossem proibidas o ensino era obrigatoriamente em alemão: "nas escolas começou-se a açoitar barbaramente as crianças que não queriam falar e rezar em alemão [...] os pais que saíssem em defesa dos filhos eram processados". (Stanislaw; Zychowski, 1963, p. 126). Apesar de existirem hostilidades contra as populações polonesas convém destacar que, na dominação prussiana, o índice de analfabetismo era baixo, embora a intenção fosse ampliar a dominação pela consequente imposição da cultura germânica afetando diretamente o ensino escolar.

O ensino elementar nos territórios sob domínio russo possuía uma situação ainda mais restritiva. O funcionamento das escolas era proibido, bem como a língua, tanto no uso cotidiano, quanto em qualquer manifestação pública ou religiosa. Para autores como Dembicz e Kieniewicz (2001, p. 31) e Gardolinski (1958), a Rússia proibiu escolas a fim de manter o povo na ignorância e visar a um processo forçado de assimilação da cultura russa. Para Malikoski (2014) os 120 anos da dominação russa tiveram como consequência direta o empobrecimento das regiões ocupadas e o surgimento de um contingente considerável de analfabetos. Entretanto, apesar das proibições russas a cultura étnica era reforçada pela língua e religiosidade nas famílias. Kieniewicz (1996) afirma que havia formação de uma consciência nacional polonesa nas famílias, nas paróquias e, onde era possível, em escolas clandestinas.

O ensino escolar, apesar de ser proibido oficialmente, acontecia na família, sendo a mãe e a avó as responsáveis por instruir as crianças na língua polonesa e nas práticas culturais próprias de seu grupo. Os poloneses, mesmo não possuindo um estado político próprio, mantiveram seus hábitos e práticas de aprendizagem fundamentadas na utilização da língua e nas demais dimensões de seu processo cultural e identitário.

As populações polonesas sob o domínio austríaco, apesar de possuírem maior liberdade para gerirem suas instituições, não contavam com número suficiente de escolas, sendo elevado o número de analfabetos. Mais uma vez o problema era a posse de terras e a conjuntura econômica, que não trazia progresso para a população polonesas 
desse território. Havia um grande contingente populacional que, atraído por propagandas de companhias de navegação marítimas, via na emigração a oportunidade de possuir terras e liberdade política.

\section{A formação de iniciativas escolares entre imigrantes poloneses no Rio Grande do Sul}

O marco do inicial da imigração polonesa para o Rio Grande do Sul está situado no ano de 1875, quando 26 famílias se fixaram na Colônia Conde D`Eu, hoje uma pequena comunidade do interior do município de Carlos Barbosa, com poucos traços conservados dessa imigração. Apenas o sino da capela doado por um imigrante polonês se encontra ainda nas dependências da capela desta comunidade.

Quando os poloneses chegaram ao Brasil havia dificuldades com o vernáculo e mesmo a interação com outros grupos de imigrantes era de certa forma limitada por causa do desconhecimento da língua portuguesa. Eram constantes os deslocamentos para regiões diferentes de onde inicialmente estavam instalados. Por ser considerado o terceiro grande grupo de imigrantes a chegar, após alemães e italianos, ficaram com os locais mais longínquos e de difícil acesso do Rio Grande do Sul. Nesse processo de instalação e de deslocamentos dos lotes coloniais originais, em busca de melhores condições de subsistência, formaram comunidades homogêneas, constituídas por meio da cultura étnica. Essas comunidades isoladas foram, em muitos municípios do Rio Grande do Sul, o espaço propício de formação de um processo de ensino, motivado pela falta de escolas públicas e pela tentativa de preservação da cultura étnica.

A implantação de escolas públicas era propalada como uma das principais preocupações dos governantes desde o período Imperial e também após a proclamação da República. Porém, a organização destas nos núcleos da imigração polonesa esteve relacionada às conjunturas políticas e sociais envolvidas na malograda condição de implantação da instrução pública nos diversos recantos do interior do Estado. Apesar da obrigatoriedade do ensino público primário na Província do Rio Grande do Sul ser instituída pela lei n. 771 , de 4 de maio de 1871, e reguladas por outras leis posteriores, de 1872 e 1876, para crianças de 7 até 15 anos de idade do sexo masculino e de 6 a 12 anos do sexo feminino, residentes em uma área distante não mais que um quilometro da sede da escola, grande parte das colônias com comunidades de imigrantes de diferentes grupos étnicos não possuíam escolas públicas. A disponibilidade de ensino público e gratuito eram eventos raros nos assentamentos da imigração polonesa.

Conforme o Relatório da Instrução Pública de $1883,{ }^{1}$ havia uma preocupação constante com a questão do ensino primário na província pelas autoridades governamentais. Entretanto, de acordo com Gardolinski (1977), as medidas estabelecidas pelos governantes suscitavam inúmeros debates,

confirmando a tese, então discutida, que diz serem impotentes as leis que vão muito além da opinião pública [...] o ensino primário gratuito e obrigatório para todos, a extirpação da chaga do analfabetismo, jamais passaram da esfera de projetos e ardentes desejos dos nossos esforçados governantes e políticos. (Gardolinski, 1977, p. 16)

${ }^{1}$ Relatório de Instrução Pública 1883, coleção de mensagens presidenciais, Arquivo Histórico do Rio Grande do Sul. 
A difusão do ensino estava dentre as prioridades, porém, pouco foi feito efetivamente pela difusão do ensino primário pelos poderes governamentais, tanto no Período Imperial, quanto após a Proclamação da República nas colônias de imigrantes no Rio Grande do Sul. No período do Brasil Império houve certa supervisão do ensino, bem como a participação do governo na ajuda para o pagamento de professores com o intuito de estimular para que os filhos dos colonos se constituíssem em cidadãos brasileiros (Sek, 1986). Essa circunstância visava a estimular a cultura nacional entre os imigrantes que aqui foram instalados.

Referente aos problemas de estruturação da instrução pública, outra circunstância importante era a questão do idioma falado pelos diversos grupos de imigrantes. Havia dificuldades em organizar escolas públicas com professores que atendessem conjuntamente os diversos grupos. Nesse sentido, para Schneider (1993), haviam dificuldades de se encontrar professores que compreendessem as línguas e dialetos que os imigrantes falavam nas colônias habitadas por diferentes nacionalidades. Nesse sentido, era necessário compreender o que as crianças falavam para depois poder ensinar.

Essa conjuntura deixou o ensino primário nas mãos dos imigrantes poloneses com suas especificidades étnicas. Dentre essas especificidades destaca-se a utilização da língua polonesa nos espaços de ensino e aprendizagem. Conforme Gardolinski (1977), "nesse estado de coisas, os imigrantes poloneses, quando se convenceram da impossibilidade de auxílio por parte do governo, na construção de escolas ou na organização do ensino primário, tomaram a si a solução do problema escolar" (p. 17). Dessa forma, quando as autoridades não mais reuniam condições suficientes de desenvolvimento de um sistema de ensino público que abrangesse todas as localidades do interior do Estado, tanto de imigrantes poloneses, quanto de outros grupos, começouse a admitir a iniciativa privada nos assuntos escolares.

Mediante a falta de escolas públicas nas colônias havia a necessidade que os imigrantes possuíam de implantação de escolas para proporcionar o mínimo de ensino elementar para as crianças. Mesmo a condição da maioria dos imigrantes de pouca instrução não impediu que, por iniciativa própria, buscassem o ensino escolar para seus filhos, construindo e organizando escolas comunitariamente.

Contudo, deve-se destacar que, além da falta de escolas públicas, o que incentivou os imigrantes poloneses a organizarem suas escolas foi a motivação étnica que congregasse a língua e a cultura trazida da Europa. Essa motivação foi importante para a formação de escolas nas comunidades. Da mesma forma que os imigrantes prezavam que o atendimento religioso fosse feito por um sacerdote polonês (Stawinski, 1999), ou que falasse a língua polonesa, eles almejavam que o professor fosse escolhido dentre aqueles que dominassem a língua e que fosse do grupo étnico. Conforme atas de sociedades, nas localidades e núcleos desses imigrantes, se o professor não dominasse a língua polonesa as famílias não enviavam seus filhos para a escola.

Conforme Cuber (1898), em meados da década de 1890, em ljuí, foi construída uma escola para atender a demanda de ensino público em espaço concedido pelo diretor da Colônia como forma de pagamento pelos imigrantes poloneses terem construído uma 
praça. Porém, a indicação de um professor por parte de imigrantes alemães, com o apoio de funcionários da Comissão de Terras, motivou para que construíssem outra escola, nomeando um professor que ensinasse em língua polonesa.

Em Porto Alegre, de acordo com o periódico Gazeta Handlowo-Geograficzna, editado em Lwów, território de domínio austríaco, informa-se que alguns imigrantes objetivavam a fundação de uma Sociedade Polonesa com o objetivo de manter uma biblioteca com livros escritos em polonês, ressaltando o propósito posterior da manutenção da língua para as gerações futuras, bem como o cuidado e auxílio para com os imigrantes recém-chegados. Essa referida sociedade deu origem a uma escola que passou a congregar as especificidades da cultura étnica polonesa na cidade de Porto Alegre.

Nesse sentido, a implantação de escolas em centros urbanos, como em Porto Alegre e Rio Grande, onde o ensino público abrangia uma maior parcela da população, a questão do pertencimento étnico e a busca pela organização de sociedades reforçam essa iniciativa de manter algumas especificidades étnicas. Nessas duas cidades foram criadas três escolas étnicas, uma em Rio Grande e duas em Porto Alegre. Assim, deve-se admitir o importante papel desempenhado pelos laços afetivos com o país e a cultura que os imigrantes trouxeram dos antepassados da Polônia, na condução do processo de ensino, não só nos núcleos urbanos, como também nos assentamentos rurais. Como vimos anteriormente, nos primeiros tempos da imigração polonesa no Rio Grande do Sul a conjuntura política dos territórios de onde os imigrantes procediam fez com que a maioria possuísse o mínimo de instrução, existindo também contingentes de analfabetos. Por essa razão as experiências de escolarização dos imigrantes, aliada à condição precária do ensino público na Província, compuseram um ambiente favorável à disseminação das escolas étnicas polonesas.

As primeiras escolas da imigração polonesa no Rio Grande do Sul foram fundadas pela iniciativa particular das comunidades na qual os imigrantes viviam e, portanto, sendo eles os próprios realizadores desse processo. Essas escolas se multiplicaram junto com as comunidades existentes. Nos primeiros anos ensinavam somente em língua polonesa, porém, a partir de 1920 começaram a ensinar também em língua vernácula, porque havia a necessidade de inserção dos filhos e descendentes de imigrantes no contexto nacional. Havia, também, a necessidade de atender às exigências impostas pelo governo no processo de nacionalização do ensino ainda da década de 1920, que previa, inclusive, subvenções para as escolas que ensinassem também em língua vernácula.

A maior parte das escolas polonesas era mantida pelos próprios colonos, sob a forma de mensalidades pagas pelos pais dos estudantes, seja em dinheiro ou alimentos repassados diretamente para o professor. Como ressalta Luporini (2012), "os poloneses que imigraram para o Brasil eram, em sua maioria, trabalhadores braçais. O que impressiona é o fato de serem capazes de criar uma rede de escolas e de professores" ( $p$. 9). Essa situação foi caracterizada pela formação de sociedades escolares organizadas, que contribuíram na formação e difusão de um sistema de ensino nas comunidades de imigração polonesa.

Antes mesmo do surgimento das primeiras sociedades, em alguns núcleos coloniais, as crianças estudavam em casas que comportassem uma rudimentar sala de aula, atendidas por professores selecionados na própria comunidade, dentre os que 
apresentassem alguma instrução ou domínio do conhecimento mínimo necessário para o magistério. Segundo Gardolinski (1977) logo que construíam a igreja e a sede da sociedade, edificavam também uma escola. Inicialmente ensinavam-se em língua polonesa os rudimentos da escrita, da leitura, dos cálculos, a história da Polônia, geografia e artes.

Uma das primeiras escolas polono-brasileiras no Rio Grande do Sul, com espaço mais organizado, foi criada em 1897, mantida pela Sociedade Concórdia em Porto Alegre. Porém, iniciativas escolares rudimentares foram identificadas nas colônias pioneiras como São Marcos e Santa Teresa na Serra Gaúcha. Klobukowski (1898), viajante da Galícia de domínio austríaco, encarregado de visitar os núcleos da imigração polonesa no Brasil, da sua passagem pela Colônia São Marcos, em 1896, relata ter encontrado um espaço construído que servia, ao mesmo tempo, de capela e de escola com o intuito de promover o ensino entre as crianças: "Nesse espaço não se ouviam missa ou cânticos religiosos, mas crianças aprendendo e ensinando" (p.159). Conforme o autor não existia um professor dito profissional, mas crianças mais novas ensinadas pelas mais velhas. Em seguida, após visitar os núcleos poloneses da Colônia Alfredo Chaves, o autor afirma ter encontrado, na Linha Ernesto Alves, um professor chamado de Lewinski, que lecionava aos imigrantes poloneses na Colônia Guaporé. Conforme publicado no almanaque Kalendarz Polski, em 1898, temos a relação dos professores profissionais que atuavam no Brasil. No Rio Grande do Sul podemos observar o nome do professor Lewinski. Considerando as fontes consultadas até então o nome do professor Lewinski aparece como um dos primeiros professores a lecionar entre os imigrantes poloneses no Rio Grande do Sul antes de 1896.

Ainda em relação às primeiras iniciativas escolares, Klobukowski (1898) relata que no ano de 1896, quando estivera na Colônia ljuí, existiam duas escolas: uma escola pública, comandada por um imigrante alemão, e uma escola privada. Por seu incentivo, no dia 17 de maio de 1896, foi fundada a sociedade Tadeusz Kosciusko, constando no primeiro parágrafo do estatuto a organização e manutenção de uma escola. Segundo Cuber (1898), na Colônia ljuí também estaria sendo construída uma escola, com frequência de 10 a 20 crianças. Porém, como ressalta o autor, existiam na região cerca de 200 crianças em idade escolar e muitas estavam sendo privadas do ensino. Por meio de lideranças existia nas colônias a preocupação em buscar a construção de escolas ou espaços de educação para as crianças desse grupo étnico, principalmente motivada por sacerdotes católicos que começavam a organizar as primeiras escolas nas pequenas capelas.

De acordo com registros paroquiais na Colônia de Dom Feliciano, em setembro de 1891, uma capela construída pelos imigrantes poloneses passou a ser utilizada como escola. Essa iniciativa de recorrer às capelas como espaços de ensino, junto com as atividades religiosas, era uma prática utilizada inicialmente nos núcleos de imigrantes poloneses. Conforme aspectos até aqui apresentados, compreendemos que esses primitivos espaços educativos foram primordiais no desenvolvimento de uma consciência para a importância do ensino elementar nos núcleos da imigração polonesa, advindo da necessidade de escolarização. Por essa razão, se considerarmos que os maiores contingentes de imigrantes chegaram ao Rio Grande do Sul a partir de 1890 e que logo 
que era construída uma capela, os colonos também organizavam uma escola, conclui-se que nas diversas colônias houve preocupação com a escolarização por parte dos imigrantes poloneses.

Entretanto, essa preocupação não era unânime entre os colonos. De acordo com Cuber (1898), em relação aos primórdios da Colônia ljuí, quando ainda os núcleos estavam sendo formados, havia colonos que pouco se importavam com a educação de seus filhos, situação também comum em outros grupos de imigrantes:

A situação escolar ficando na dependência dos colonos apresentava sintomas bastante tristes e, por isso, a educação das crianças, frequentemente, tornava-se impraticável. Aqui no Brasil, nenhum pai de família poderá ser perdoado, se porventura não mandar os filhos para a escola, lá onde ela existe. O pai que não se interessa pela educação dos seus filhos comete um grave pecado: o filho, por sua vez, que não aprendeu ao menos, ler, escrever e contar, em razão da irracional cobiça de lucro de progenitores, que o mandaram plantar milho ou pastorear o gado e, com este procedimento ter-lhe-á fechado, possivelmente grandes perspectivas para o futuro - com certeza há de recordar - seus pais, mais tarde, com ressentimento e amargura. (p. 52)

Cuber (1898) argumenta sobre a importância da instrução, principalmente para evitar explorações de outros imigrantes, na condução mais racional dos negócios e na possibilidade de prestigiar iniciativas patrióticas polonesas, o que, na visão do autor, seria inacessível às pessoas iletradas. Para o autor, havia em alguns colonos o seguinte pensamento: "meu avô, meu pai e eu não sabemos ler, portanto, isto também será supérfluo para meu filho" (p. 52).

A educação elementar na casa de colonos ou em espaços improvisados em igrejas enfrentavam alguns problemas. Do período analisado uma das principais caracterizações referentes aos problemas nas escolas era a falta de professores qualificados, considerados uma raridade nos assentamentos de colonos poloneses no Rio Grande do Sul. Essa situação estava associada às condições existentes para o ensino nos núcleos da imigração. Conforme suplemento da Gazeta Handlowo-Geograficzna,

todo aquele que sabe como é pouco lucrativo, sob o aspecto material, o trabalho do professor nas colônias, e com quantas dificuldades muitas vezes precisa lutar ali o mestre para poder, de alguma maneira, dirigir uma escola, essa pessoas que, afastadas do mundo e da civilização, condenadas à penúria (que muitas vezes beira a miséria), à falta de companhia adequada, à falta de livros, revistas e quaisquer diversões culturais, dedicam-se com entusiasmo ao trabalho pelo bem do nosso povo, organizando-o, despertando nele o espírito cívico e dando-lhe aquilo que mais Ihe falta: a educação. $(1900$, n. 2)

Os poucos professores com formação e condições de ensino, devido aos baixos salários, buscavam desenvolver outras atividades mais rentáveis, pois o pagamento oferecido nas comunidades mal servia para a subsistência. A indisponibilidade de livros ou manuais eram também situações frequentes nos núcleos de imigração antes de 1900. Nessa perspectiva, nos acervos e museus de diversas cidades do Rio Grande do Sul impressiona a grande quantidade de livros religiosos existentes que foram trazidos com 
os imigrantes. Em algumas localidades, na falta de manuais ou livros apropriados para o ensino, os professores improvisados utilizavam orações, história de santos ou a própria Bíblia como material de ensino.

Em fins do século 19, conforme análise de Gluchowski (2005), o ensino étnico polonês no Rio Grande do Sul era deficiente. Afirma o cônsul que, em Porto Alegre, não existiam escolas e apenas um padre belga, chamado de Moreau, fundou uma escolinha na paróquia onde residiam muitos poloneses. Da mesma forma que Porto Alegre, o autor cita que em Jaguari, Guarani e São Feliciano não haviam escolas, somente aulas particulares em domicílios. Contudo, em ljuí, lecionava um colono de nome J. Hamerski e, em Ernesto Alves, o professor Lewinski, já referido anteriormente.

Por essa razão reconheço que a análise do cônsul se refere aos espaços institucionalizados com professores profissionais dedicados ao ensino. Como o próprio cônsul admite, havia algumas aulas particulares em domicílios, uma característica importante do processo de ensino entre os imigrantes até o fim do século 19 no Rio Grande do Sul.

Entretanto, essa era uma realidade presente no Brasil para com os imigrantes poloneses desse período. A revista Przeglad Emigracyjny, de 1892, classificava a educação para o grupo étnico polonês em um nível muito baixo, apesar da liberdade que tinham em possuir escolas. Contudo, a revista responsabiliza essa situação pela falta de empenho do clero que atendia às colônias e não se preocupava com o bem estar moral e material desses imigrantes. Essa crítica foi frequentemente dirigida também pelo cônsul polonês Gluchowski (2005): "O colono sente cada vez mais a necessidade da escola, mas infelizmente não compreende nem o seu significado nem o seu papel, nem muito menos a necessidade de maiores despesas em favor dela" (p. 167). Por essa razão, certa reação e consolidação de um sistema de ensino para com os imigrantes poloneses no Rio Grande do Sul aconteceu somente a partir de 1896, quando foram organizadas as primeiras sociedades escolares por iniciativa do viajante polonês Klobukowski (1898), enviado pela Sociedade Geográfica e Comercial de Lwów, território de domínio austríaco.

O fato da passagem do viajante pelas colônias do Rio Grande do Sul e o incentivo para a organização de sociedades e escolas deram uma nova perspectiva para o processo de ensino étnico entre os imigrantes poloneses. Em 1896 foram organizadas quatro sociedades: em Jaguari, ljuí, Rio Grande e Porto Alegre. Por meio da fundação dessas sociedades também foram organizadas as primeiras escolas em espaços mais apropriados para o ensino, que começam a empreender o processo de educação e a organização de escolas com a contratação de professores melhor qualificados, com livros didáticos e organização pedagógica. O ano de 1896 pode ser considerado o marco inicial da consolidação de um sistema de ensino pela organização das sociedades escolares presentes em todas as comunidades organizadas de imigrantes poloneses. Deste período em diante muitas escolas foram organizadas e constituídas nos núcleos de imigração polonesa.

A partir da consolidação das sociedades e a vinda de religiosos católicos, as escolas étnicas polonesas estavam organizadas em duas orientações: escolas leigas ou escolas confessionais. Nas escolas leigas, após a criação da sociedade, as comunidades construíam as escolas ou ofereciam o espaço para o ensino. Responsabilizavam-se pela compra de mobiliário e material didático e pelo pagamento dos professores. No início não 
contavam com nenhum tipo de ajuda governamental, mas, em anos posteriores, algumas escolas começaram a receber algum subsídio do Estado ou dos municípios para o pagamento dos professores, como incentivos para lecionarem em vernáculo. Por sua vez as escolas confessionais eram vinculadas às congregações religiosas ou a algum sacerdote que cobravam mensalidade dos alunos, sendo mantidas e administradas com base em preceitos religiosos.

A partir de 1920, com a Polônia como Estado independente, no cenário pós-Primeira Guerra Mundial, os núcleos coloniais de imigrantes poloneses no Rio Grande do Sul e em outros Estados começaram a receber acompanhamento direto por meio do consulado polonês em Curitiba, que enviava professores, livros didáticos e organizava cursos para professores. Foi partir desse período que se consolidam as primeiras associações de escolas e professores, dentre elas as mais importantes foram a Kultura e a Oswiata.

A Kultura tinha uma orientação leiga e liberal. Congregava a Associação dos Professores das Escolas Polonesas Particulares no Brasil. No Rio Grande do Sul, segundo censo realizado pelo cônsul polonês Kasimierz Gluchowski, ainda em 1924, havia 22 escolas da Kultura. A Oswiata, que em português significa Educação, possuía seis escolas no Estado. Essas escolas, com uma orientação confessional, geralmente vinculada a religiosos católicos, estavam congregadas à Associação dos Professores das Escolas Polonesas Cristãs. Ainda segundo Gluchowski (2005) havia também 20 escolas ditas isoladas e que não possuíam filiação.

Segundo o censo escolar da imigração polonesa no Brasil, realizado pelo Consulado da Polônia de Curitiba, na véspera da nacionalização do ensino, em 1938, havia no Rio Grande do Sul 128 escolas étnicas polonesas, com 4.560 alunos, nas quais lecionavam 114 professores. Dessas escolas 117 tinham ensino bilíngue - português e polonês -, dez possuíam ensino em português e uma contava com ensino somente em polonês. Ainda em relação a essas escolas 19 estavam fechadas temporariamente por falta de professores e três em organização, perfazendo um total de 106 escolas em atividade. No Brasil esse número, de acordo com Malczewski (1998), sem contar as escolas fechadas, foi de 330, sendo 293 escolas leigas e 37 confessionais, concentradas, principalmente, no Estado do Paraná. Nas referidas escolas 287 professores ensinavam um total de 9.316 crianças, matriculadas regularmente até 1937.

\section{Considerações finais}

A cultura étnica foi uma forma de condução da produção de instituições escolares da imigração polonesa e seu processo dinâmico conduziu os indivíduos à preservação de simbologias, valores e conhecimentos que atuaram nas transformações dos espaços sociais. As representações e significados culturais étnicos, formada pelo conjunto desses valores, compreendendo desde a maneira de pensar até seus atributos culturais, dentre eles, a língua e suas instituições, as quais figuram dentre as representações simbólicas, congregaram os indivíduos no seu pertencimento étnico. O conteúdo étnico se desenvolveu num determinado espaço, considerando suas peculiaridades e a apropriação desse território. Etnia e cultura estão para uma determinada territorialidade e existem estruturas que determinam que uma significação cultural se desenvolva e se configure de acordo com determinado modo. 
Por esse motivo as escolas étnicas polonesas no Rio Grande do Sul podem ser pensadas por meio dos espaços construídos, em localidades rurais e urbanas habitadas pela imigração polonesa com suas especificidades culturais institucionalizadas. É nesse espaço de construção étnica que se formou o processo de escolarização das crianças polonesas no Rio Grande do Sul. Parece-nos importante salientar a especificidade da imigração polonesa em relação a outros grupos de imigrantes no que se refere à questão escolar e mesmo de cidadania, pois a maior parte desses imigrantes provinha de regiões sob o domínio russo, alemão ou austríaco. Esses países tiveram nenhum interesse em favorecer ou acompanhar as organizações culturais polonesas na condição de dominados e muito menos ainda na condição de emigrados. Por isso é importante realçar que, não obstante, em ambiente desfavorável, eles recorriam a uma prática doméstica de ensino da leitura e da escrita, mesmo que rudimentar, ministrada pelas mães e avós. Essa prática continuou nas famílias desse grupo de imigrantes em sua fase inicial no Rio Grande do Sul, quando ainda não haviam instalado suas escolas étnicas. Os imigrantes poloneses trouxeram consigo uma limitada noção de tradição escolar, porém, empreenderam por seus esforços um sistema de ensino étnico.

Passados 140 anos do início da imigração polonesa para o Rio Grande do Sul podemos salientar que os poloneses constituíram uma importante corrente imigratória, com traços presentes em muitos municípios e que, de modo diferente dos grupos étnicos majoritários, tiveram acesso a sobras de terras muitas vezes impróprias para subsistência, seja pela distância entre si, seja pela sua dispersão entre aglomerações de outros grupos étnicos. Não formaram um grande conjunto de comunidades, como as estabelecidas por alemães nos vales do Rio Caí e do Rio dos Sinos, ou por italianos na Serra. Entretanto, constituíram estruturas comunitárias em núcleos rurais e urbanos que favoreceram a integração étnica, com destaque para as escolas, salões da sociedade e capelas.

As escolas étnicas polonesas conseguiram desempenhar seu papel na ação educadora dos filhos e mesmo de crianças descendentes de outras nacionalidades. Contudo, não conseguiram atingir todas as crianças em idade escolar nas colônias porque havia falta de recursos para a manutenção das escolas, material didático e professores. Em alguns casos havia também desentendimentos de ordem ideológica, com reflexos nas organizações comunitárias, como as organizações de sociedade leigas e religiosas. É preciso salientar ainda que, em muitas famílias, as crianças começavam a trabalhar desde muito cedo e, por vezes, a frequência escolar ficava em segundo plano. Em relatos de ex-alunos e em documentos há referências sobre o salário dos professores pago pelas comunidades. Como se constatou em outros grupos étnicos o salário pago ao professor era irrisório, sendo necessário desempenhar outras atividades para conseguir o sustento. Nas condições precárias de sobrevivência, o investimento em educação por parte dos colonos era pouco expressivo.

Outro aspecto que merece atenção é que na véspera do processo de nacionalização do ensino, em 1938, das 128 escolas étnicas polonesas no Estado mais de 90\% funcionavam com ensino bilíngue, o que retrata o interesse desse grupo de imigrantes em integrar-se na cultura nacional e, ao mesmo tempo, receber subvenções para a manutenção do ensino. Nesse sentido, o processo escolar das escolas étnicas polonesas 
teve um desenvolvimento próprio, com as características culturais trazidas com os imigrantes, somando-se ao novo contexto da colonização no Rio Grande do Sul por meio de constantes adaptações e readaptações.

Dessa forma as fontes examinadas permitem concluir que houve um processo escolar étnico entre imigrantes poloneses no Rio Grande do Sul de 1875 a 1938, interrompido com a nacionalização compulsória do ensino, promovida pelo Estado Novo. Essa experiência perdura ainda na memória de muitos descendentes de imigrantes que vivenciaram esse processo escolar étnico. Essas escolas foram importantes para a manutenção de representações e resignificações da cultura étnica polonesa no Estado. O fechamento das mesmas gerou diversos conflitos por ocasião da campanha de nacionalização promovida pelo Estado Novo, em que foram proibidas e fechadas, sem serem adequadamente substituídas por escolas públicas.

Podemos concluir que no Rio Grande do Sul, até pouco antes do processo de nacionalização de ensino em 1938, em praticamente todas as comunidades havia uma escola instituída com o ensino elementar. A grande maioria estava em funcionamento efetivo, conforme atestam os relatórios do consulado de Curitiba de 1937.

Enfim, esta pesquisa sobre o processo escolar entre imigrantes poloneses no Rio Grande do Sul foi uma tarefa instigante porque implicou na busca por fontes dispersas. Isso exigiu atenção para pequenos sinais, vestígios, lembranças, resquícios de significados e sentidos que os imigrantes deixaram nas suas trajetórias.

\section{Referências}

BRASIL. Decreto-lei $n$. 406, de 4 de maio de 1938: dispõe sobre a entrada de estrangeiros em território nacional. Coleção de leis do Brasil - 1938, p. 92, v. 2. Rio de Janeiro: Diário Oficial da União, 6 maio 1938, seção 1, p. 8494.

BRASIL. Decreto-lei n. 1545, de 25 de agosto de 1939: dispõe sobre a adaptação ao meio nacional dos brasileiros descendentes de estrangeiros. Coleção de decretos de 1931 a 1945. Rio de Janeiro: Diário Oficial da União, 25 ago. 1939, seção 1, p. 8502.

CHARTIER, Roger. A história cultural: entre práticas e representações. Lisboa: Difel, 1988.

CUBER, Antoni. Z nad Uruguayu. In: ZDANOWSKI, Felix, Kalendarz Polski na rok zwyczajny 1898. Porto Alegre: edição do autor, 1898.

DEMBICZ, Andrzej; KIENIEWICZ, Jan. Polônia e polono-brasileiros. Varsóvia: Cesla, 2001.

FOUCAULT, Michel. As palavras e a coisas: uma arqueologia das ciências humanas. São Paulo: Martins Fontes, 1987.

FOUCAULT, Michel. Microfísica do poder. Rio de Janeiro, Graal, 2000.

GARDOLINSKI, Edmundo. Escolas da colonização polonesa no Rio Grande do Sul. Porto Alegre: EST; Caxias do Sul: UCS, 1977.

GARDOLINSKI, Edmundo. Imigração e colonização polonesa. In: BECKER, Klaus (org.). Enciclopédia rio-grandense. Canoas: Regional, v. 5, 1958, p. 3-114.

GAZETA HANDLOWO-GEOGRAFICZNA. Ano II, n. 10, 1900, p. 76. [Acervo Sociedade Polônia - Porto Alegre/RS.] 
GLUCHOWSKI, Kazimierz. Os poloneses no Brasil. Porto Alegre: Rodycz \& Ordakowski, 2005.

HALL, Stuart. A identidade cultural na pós-modernidade. Rio de Janeiro: DP\&A, 2006.

HANNERZ, Ulf. Fluxos, fronteiras, híbridos: palavras-chave da antropologia transnacional. In Mana - Estudos de Antropologia Social, Rio de Janeiro, v. 3, n. 1, 1997, p. 7-39.

KALENDARZ POLSKI, 1898. Fotocópia. Acervo da Sociedade Polônia - Porto Alegre/ RS.

KIENIEWICZ, Jan. Os poloneses e sua história. In: DEMBICZ, Andrzej; KULA, Marcin, Relações entre Polônia e Brasil: passado e presente. Varsóvia: Cesla, 1996, p. 19-38.

KŁOBUKOWSKI, Stanisław. Wspomnienia z podróży po Brazylii, Argentynie, Paragwaju, Patagonii i ziemi ognistej. Lwów: Nakładem Gazety Handlowo - Geograficznej. Z drukarni W. A. Szyjkowskiego, 1898.

KREUTZ, Lúcio. Diferenças étnicas e educação intercultural: a partir de que entendimento de etnicidade? Série-Estudos, Campo Grande, n. 15, 2003, p. 81-92.

KREUTZ, Lúcio. Escolas étnicas na história da educação brasileira: a contribuição dos imigrantes. In: STEPHANOU, Maria (org.). Histórias e memórias da educação no Brasil. Petrópolis: Vozes, 2009, p. 150-165.

KREUTZ, Lúcio. Etnia e educação: perspectivas para uma análise histórica. In: SOUZA, Cyntia Pereira de; CATANI, Denise Bárbara (org.). Práticas educativas, culturas escolares, profissão docente, São Paulo: Escrituras, 1998, p. 93-109.

KREUTZ, Lúcio. O professor paroquial: magistério e imigração alemã. Pelotas: Seiva, 2004.

LIVRO DE ATAS DA SOCIEDADE POLÔNIA - BRASPOL. Porto Alegre/RS, 1939.

LUPORINI, Teresa Jussara. Educação polonesa: os fundamentos da educação escolar étnica revisitados. In: LUCHESE, Terciane Ângela; KREUTZ, Lúcio (orgs.). Imigração e educação no Brasil: histórias, processos e práticas escolares. Santa Maria: UFSM, 2011, p. 165-190.

MALCZEWSKI, Zdzislaw. A presença dos poloneses e da comunidade polônica no Rio de Janeiro. Varsóvia: Cesla, 1998.

MALIKOSKI, Adriano. Escolas étnicas dos imigrantes poloneses no Rio Grande do Sul, (1875-1939). Caxias do Sul: UCS, 2014. 220f. Dissertação (mestrado em Educação). Programa de Pós-Graduação em Educação, Universidade de Caxias do Sul.

PARAISO, Marlucy Alves. Metodologias de pesquisas pós-críticas em educação e currículo: trajetórias, pressupostos, procedimentos e estratégias analíticas. In: MEYER, Dagmar Estermann; PARAISO, Marlucy Alves (org.). Metodologias de pesquisas póscríticas em educação. Belo Horizonte: Mazza, 2012, p. 23-46.

PESAVENTO, Sandra Jatahy. História e história cultural. Belo. Horizonte: Autêntica, 2008. POUTIGANT, Philippe; STREIFF-FENART, Jocelyne. As teorias da etnicidade. São Paulo: Unesp, 1998.

PRZEGLAD. Towarzystw i szkol Polskich w Brazylij. Relatório das sociedades e escolas polonesas no Brasil - Estado do Rio Grande do Sul - Realizado pelo consulado da Polônia em Curitiba, 1937. Museu Municipal, Áurea/RS.

Relatório de Instrução Pública 1883 - Coleção de Mensagens Presidenciais - Arquivo Histórico do Rio Grande do Sul - AHRGS, Porto Alegre/RS.

Revista Przeglad Emigracyjny, 1892 - Acervo do Padres Vicentinos - Curitiba/PR. 
SCHNEIDER, Regina Portela. A instrução pública no Rio Grande do Sul (1770-1889). Porto Alegre: Ufrgs/EST, 1993.

SEK, Jan. Szkolnictwo Polonijne w Brazylij w latach 1941-1980. Lublin: Szkolnictwo w XX wiek, 1986.

STANISLAW, Arnold; ZYCHOWSKI, Marian. Esboço da história da Polônia. Varsóvia: Polônia, 1963.

STAWINSKI, Alberto Victor. Primórdios da imigração polonesa no Rio Grande do Sul (1875-1975). Porto Alegre: EST, 1999.

WACHOWICZ, Ruy Christovam. As escolas da colonização polonesa no Brasil. Curitiba, Champagnat, 2002.

WACHOWICZ, Ruy Christovam. O camponês polonês no Brasil: raízes medievais da mentalidade emergente. Curitiba: Universidade Federal do Paraná, 1974.

ADRIANO MALIKOSKI é mestre em Educação, estudante do curso de doutorado em Educação na UCS e professor na mesma universidade.

Endereço: Rua das Rosas, 4600 - 90270-000 - Flores da Cunha - RS.

E-mail: adriano.malikoski@hotmail.com.

LÚCIO KREUTZ é doutor em educação, pesquisador I no CNPQ, atua na Universidade de Caxias do Sul.

Endereço: Rua Epifânio Fogaça, 430 - 93022-620 - São Leopoldo - RS.

E-mail: lkreutz@terra.com.br.

Recebido em 17 de fevereiro de 2014.

Aceito em 23 de maio de 2016. 